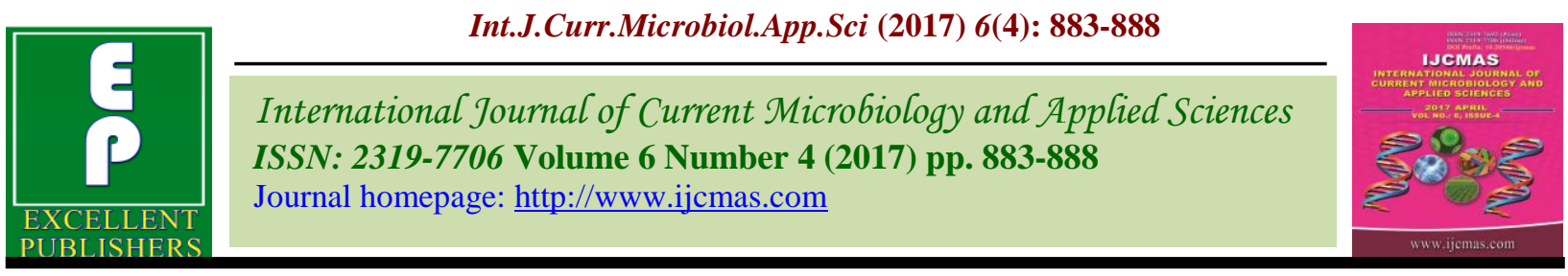

Original Research Article

https://doi.org/10.20546/ijcmas.2017.604.111

\title{
Isolation and Evaluation of Azotobacter spp. from Different Crop Rhizosphere
}

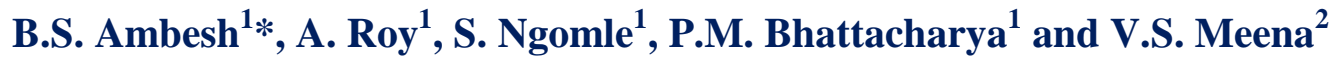 \\ ${ }^{1}$ Department of Plant Pathology, Uttar Banga Krishi Viswvidyalaya, \\ Pundibari-736165, Coochbehar, West Bengal, India \\ ${ }^{2}$ Crop Science Division, ICAR Headquarters, Krishi Bhavan, New Delhi -110 001, India \\ *Corresponding author
}

\section{A B S T R A C T}

Keywords

Azotobacter, chilli and crop rhizosphere.

Article Info

Accepted:

06 March 2017

Available Online:

10 April 2017

\begin{abstract}
In this study, eleven soil samples were collected from Terai zone of West Bengal. The Azotobacter were isolated by serial dilution method from each sample in specific Azotobacter agar (Mannitol) and incubated at $28 \pm 2{ }^{\circ} \mathrm{C}$ for 48 hour than kept in refrigerator. The best strains of Azotobacter were evaluated by in-vitro and in-vivo screening. The highest population and nitrogen fixation ability was recorded in rhizosphere soil of Mathura tea garden designated as UBAZ-5 $\left(7.3 \times 10^{9}\right)$. UBAZ-5 was also found significantly superior in physical characteristics of chilli plant. The shoot length (12.03 $\mathrm{cm})$, root length $(14.33 \mathrm{~cm})$, shoot fresh weight $(1.26 \mathrm{~g})$ and root fresh weight $(0.55 \mathrm{~g})$, shoot dry weight $(0.30 \mathrm{~g})$ and root dry weight $(0.21 \mathrm{~g})$ of UBAZ-5 bioinoculated chilli plants were found to be superior to un-inoculated check. Hence, use of bioinoculant will increase the physical characteristics and further increases crop productivity.
\end{abstract}

\section{Introduction}

In recent years there is high negative impact due to the usage of agro-chemical on both human and environment, challenging the agriculturalists demanding for an alternative approach to combat it. Biofertilizers have emerged as a promising component of integrating nutrient supply system in agriculture which is more eco-friendly and natural. They contain useful microorganisms which could colonize the rhizosphere and promote plant growth through increasing the supply or availability of essential nutrients to the plants (Vessey, 2003). Nitrogen is an important component which provided as chemical fertilizer and possesses hazards to soil health. Azotobacter is free living symbiotic $\mathrm{N}_{2}$ fixing biofertilizer, which fix atmospheric $\mathrm{N}_{2}$ to its available forms i.e. nitrate form. Besides $\mathrm{N}_{2}$ fixation, Azotobacter synthesizes and secretes considerable amounts of biologically active substances like B vitamins, nicotinic acid, pantothenic acid, biotin, heteroxins, gibberelins etc. which enhance root growth of plants (Rao, 1986). Another important characteristic of Azotobacter association with crop improvement is secretion of ammonia in the rhizosphere in the presence of root exudates, which helps in modification of nutrient uptake by the plants (Narula and Gupta, 1986). Therefore this study was designed to evaluate the influence of Azotobacter on 
growth and phenology of chilli plants in the Terai zone of West Bengal.

\section{Materials and Methods}

\section{Collection of soil}

11 soil samples collected from different districts like Coochbehar, Jalpaiguri and Alipuduar of North Bengal from different crop rhizosphere. The soil sample were collected in pored polythene bags and stored at room temperature.

\section{Isolation of Azotobacter spp.}

The Azotobacter spp. was isolated by serial dilution pour plate technique given by Subba Rao, 1986. $1 \mathrm{gm}$ of soil was mixed with $9 \mathrm{ml}$ sterile distilled water properly then from this $1 \mathrm{ml}$ of soil solution was transferred to another $9 \mathrm{ml}$ test-tube. Likewise $10^{-6}$ dilution was made and transferred to Azotobacter specific medium. The Azotobacter colonies were large ovoid pleomorphic in shape and this was purified on Azotobacter specific medium slant to preserve the culture.

\section{Assessment of viable population}

11 isolates of Azotobacter spp. (Table 1) viable population were estimated by 3 tube most probable number (MPN) method by Alexander (Cochran, 1950).

Screening of potential Azotobacter spp. isolates based on $\mathrm{N}_{2}$ fixation in broth culture

Total nitrogen fixation by the Azotobacter isolates in the growing medium is quantified by the method (Johan Kjeldahl 1883).

(T-B) x $0.05 \times 14$ x Volume of broth Total $\mathrm{N}=$

Volume taken
Screening of Azotobacter strains in field condition

The nitrogen fixing ability of the isolated Azotobacter spp. was determined in garden soil by pot cultivation method by assessed the growth of chilli. The chilli seed were treated with different isolates of Azotobacter strains and sown in pro-trays. The control is devoid of inoculums. The pots were watered regularly and the effect of bacterial inoculum on seed germination on $8^{\text {th }}$ day was checked and then the growth of plant root and shoot length was measured at transplanting stage.

The experiment was conducted with chilli variety NS-238 using 11 isolates of Azotobacter species, treated seeds was sown in pro-trays under polyhouse condition. According to recommended dose of chilli single super phosphate @ 0.0166 gm $/ \mathrm{kg}$ of soil, muriate of potash @ $0.0025 \mathrm{gm} / \mathrm{kg}$ of soil and FYM @ 1:3 ratios mixed with soil. Azotobacter isolates were inoculated through seed dressing and sown in pro-trays and noninoculated seeds were sown as control. Watering to plants was done according to needs. Plants were allowed to grow for 40 days i.e. up to transplanting stage. Plant height, root-shoot fresh weight and dry weight were recorded after harvest.

\section{Results and Discussion}

The highest population was recorded in rhizospheric soil of UBAZ-5 $\left(7.3 \times 10^{9}\right)$ followed by UBAZ-7 (7.3x $\left.10^{8}\right)$ and UBAZ-1 $\left(2.3 \times 10^{8}\right)$ and lowest population was observed in UBAZ-6 $\left(0.9 \times 10^{5}\right)$. Azotobacter population depends on the factor such as soil temperature and organic matter which degrade plant residues and help in proliferation of microorganisms in soil (Iswaran and Marwaha, 1981). Azotobacter plays an important role in nitrogen fixation. Therefore, Azotobacter isolates were evaluated for their nitrogen 
fixation ability in broth culture. The highest nitrogen fixation was found in UBAZ-5 followed by UBAZ-3 and UBAZ-10 (37.8, 33.6 and $32.9 \mathrm{mg} / 100 \mathrm{ml}$ broth culture respectively, after 8 days of inoculation. The rate of increase in nitrogen fixation was also high in UBAZ- 5, UBAZ-3 and UBAZ-10 (Table 2 and Figs. 1 and 2). The soil of Mathura tea garden was found more of organic matter which makes the soil friable and permeates the air and water for growth of micro-organism (Haris, 1981).

The chilli seeds (Variety- NS-238) treated with different isolates of Azotobacter spp. were sown in pro-trays to examine the influence of the isolates on seedling growth at transplanting stage. Various physical characteristics like shoot length, root length, root and shoot fresh weight, root and shoot dry weight were measured and the results have been presented in table 3. The shoot lengths of the inoculated transplants viz. UBAZ-3, UBAZ-2, UBAZ-1, UBAZ-5, and UBAZ-4 were found significantly higher $(14.20 \mathrm{~cm}, 13.30 \mathrm{~cm}, 13.10 \mathrm{~cm}, 13.00 \mathrm{~cm}$ and $12.03 \mathrm{~cm}$, respectively) compared to uninoculated check $(9.60 \mathrm{~cm})$. The isolates
UBAZ-6, UBAZ-7, UBAZ-10 and UBAZ-11 were found significantly at par. The root length of inoculated transplants UBAZ-10 was significantly high $(17.03 \mathrm{~cm})$ followed by UBAZ-11, UBAZ-9 and UBAZ-5 $(15.69 \mathrm{~cm}$, $14.67 \mathrm{~cm}$ and $14.33 \mathrm{~cm}$, respectively). The effects of other isolates were significantly at par.

The fresh shoot weight was found significantly high in inoculated transplant UBAZ-5 (1.26 g) followed by UBAZ-10, UBAZ-6, UBAZ-7, UBAZ-3 and UBAZ$11(1.16 \mathrm{~g}, 1.15 \mathrm{~g}, 1.15 \mathrm{~g}, 1.14 \mathrm{~g}$ and $1.00 \mathrm{~g}$ respectively). The fresh shoot weight of inoculated transplants UBAZ-1, UBAZ-8 and UBAZ-9 were significantly at par. The dry shoot weight of biofortified transplants were found significantly high in UBAZ-5 treated seedlings $(0.30 \mathrm{gm})$ followed by UBAZ-8 $(0.23 \mathrm{~g})$, and UBAZ-3 (0.19g), while in uninoculated transplants the shoot dry weight was $0.14 \mathrm{gm}$. The root fresh weight was found highest in UBAZ-6 $(0.79 \mathrm{gm})$ followed by UBAZ-7, UBAZ-10 and UBAZ-5 (0.55gm) which differed significantly from uninoculated control.

Table.1 Detail of Azotobacter isolates isolated from different sources, location and MPN value

\begin{tabular}{|c|l|l|}
\hline Isolates & \multicolumn{1}{|c|}{ Source } & \multicolumn{1}{c|}{ Location } \\
\hline UBAZ-1 & Camelia sinensis & Cooch Behar tea garden \\
\hline UBAZ-2 & Beta vulgaris & Kalimpong \\
\hline UBAZ-3 & Musa paradisiacal & Kalimpong \\
\hline UBAZ-4 & Repository of Plant Pathology laboratory & UBKV \\
\hline UBAZ-5 & Camelia sinensis & Mathura tea garden \\
\hline UBAZ-6 & Brassica oleracea & Kalimpong \\
\hline UBAZ-7 & Saccharum spontaneum & Kalimpong \\
\hline UBAZ-8 & Bambusa vulgaris & Kalimpong \\
\hline UBAZ-9 & Camelia sinensis & Nagarakata tea garden \\
\hline UBAZ-10 & Camelia sinensis & Vijaynagar tea garden \\
\hline UBAZ-11 & Camelia sinensis & Dalgaon tea garden \\
\hline
\end{tabular}


Table.2 Variation in nitrogen fixation ability of different Azotobacter isolates

\begin{tabular}{lccc}
\hline Isolates & \multicolumn{3}{c}{ N2 fixation $(\mathbf{m g} / \mathbf{1 0 0}$ ml culture broth) } \\
\cline { 2 - 4 } & $\begin{array}{c}\text { 3 days after } \\
\text { inoculation }\end{array}$ & $\begin{array}{c}\text { 5 days after } \\
\text { inoculation }\end{array}$ & $\begin{array}{c}\text { 8 days after } \\
\text { inoculation }\end{array}$ \\
\hline UBAZ-1 & 26.22 & 27.30 & 28.00 \\
UBAZ-2 & 21.56 & 24.50 & 25.90 \\
UBAZ-3 & 26.60 & 28.70 & 33.60 \\
UBAZ-4 & 23.10 & 23.10 & 24.50 \\
UBAZ-5 & 22.40 & 25.20 & 37.80 \\
UBAZ-6 & 22.40 & 22.40 & 24.50 \\
UBAZ-7 & 24.50 & 21.70 & 24.50 \\
UBAZ-8 & 21.00 & 21.84 & 25.20 \\
UBAZ-9 & 19.60 & 22.40 & 23.80 \\
UBAZ-10 & 25.20 & 25.20 & 32.90 \\
UBAZ-11 & 21.70 & 25.90 & 30.10 \\
Control & 14.00 & 15.05 & 14.70 \\
\hline SEm \pm & 0.843 & 1.071 & 1.041 \\
CD & 2.487 & 3.160 & 3.071 \\
(P=0.05) & & & \\
\hline
\end{tabular}

Table.3 Variation in physical attributes of Azotobacter treated chilli plants at seedling stage

\begin{tabular}{lllllll}
\hline \multicolumn{1}{c}{ Isolates } & \multirow{2}{*}{$\begin{array}{c}\text { Shoot } \\
\text { length }\end{array}$} & $\begin{array}{c}\text { Root } \\
\text { length }\end{array}$ & \multicolumn{2}{l}{ Shoot weight (gm) } & Root weight (gm) \\
\cline { 5 - 7 } & & & & & & \\
\hline UBAZ-1 & 13.10 & 14.00 & 0.91 & 0.17 & 0.38 & 0.14 \\
UBAZ-2 & 13.30 & 13.33 & 0.89 & 0.14 & 0.32 & 0.12 \\
UBAZ-3 & 14.20 & 14.00 & 1.14 & 0.19 & 0.50 & 0.21 \\
UBAZ-4 & 12.03 & 12.83 & 1.10 & 0.16 & 0.48 & 0.15 \\
UBAZ-5 & 13.00 & 14.33 & 1.26 & 0.30 & 0.55 & 0.21 \\
UBAZ-6 & 9.73 & 12.27 & 1.15 & 0.15 & 0.79 & 0.14 \\
UBAZ-7 & 10.10 & 13.87 & 1.15 & 0.17 & 0.66 & 0.10 \\
UBAZ-8 & 8.40 & 13.63 & 0.70 & 0.23 & 0.39 & 0.08 \\
UBAZ-9 & 9.43 & 14.67 & 0.87 & 0.14 & 0.51 & 0.08 \\
UBAZ-10 & 10.37 & 17.03 & 1.16 & 0.16 & 0.56 & 0.09 \\
UBAZ-11 & 9.63 & 15.67 & 1.00 & 0.14 & 0.49 & 0.08 \\
Control & 9.60 & 11.67 & 0.84 & 0.14 & 0.37 & 0.07 \\
\hline SE(m) \pm & 0.591 & 0.830 & 0.031 & 0.012 & 0.021 & 0.006 \\
CD at 95\% & 1.744 & 2.449 & 0.090 & 0.035 & 0.061 & 0.019 \\
\hline
\end{tabular}


Fig.1 Population dynamics (MPN) of different Azotobacter isolates in rhizosphere soil

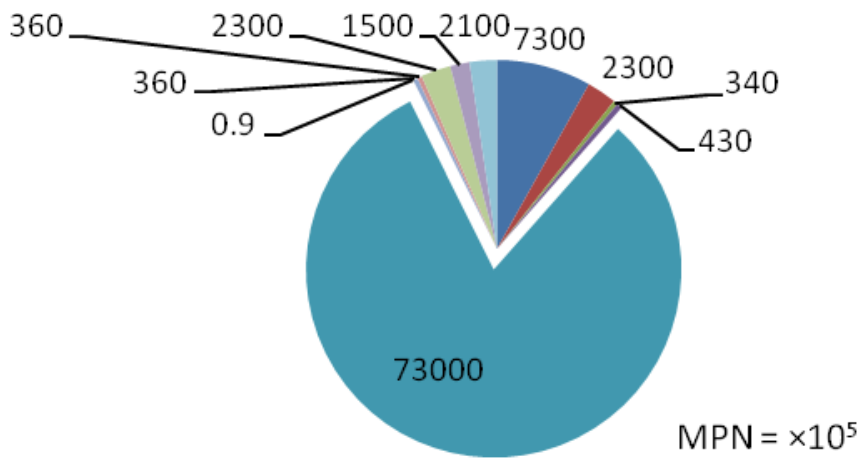

Fig.2 Potential of nitrogen fixation by different Azotobacter isolates

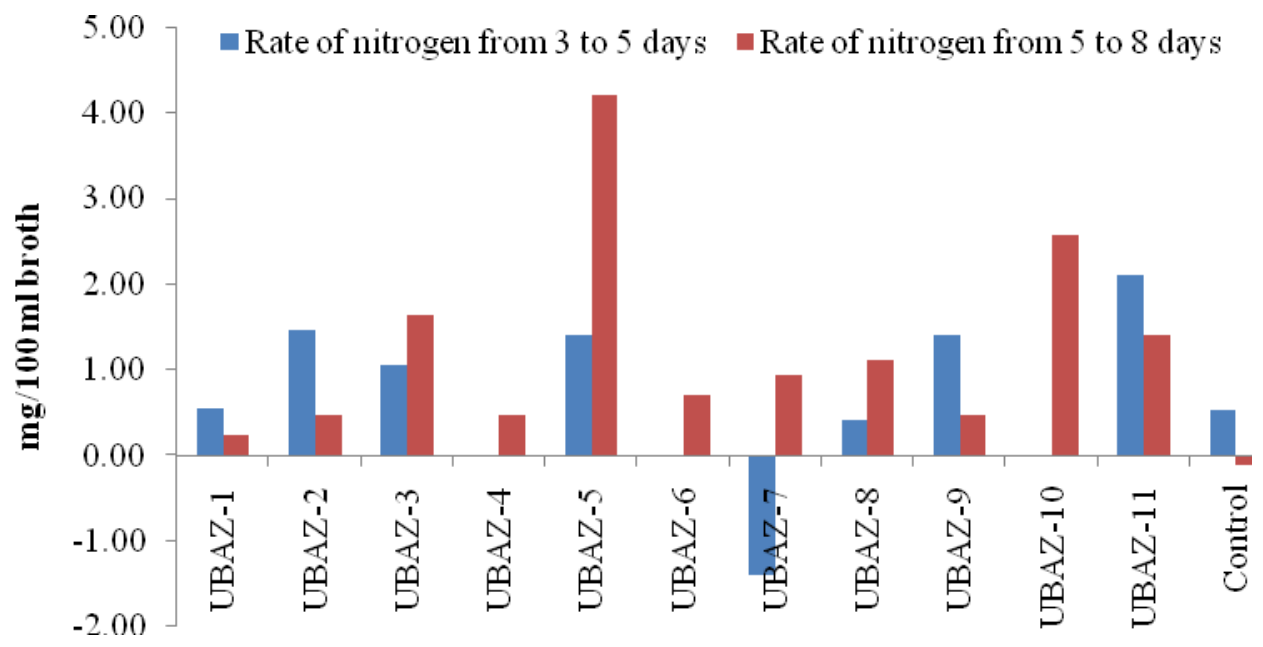

The root dry weight was found significantly high in UBAZ-5 and UBAZ-3 (0.21gm) treated transplants followed by UBAZ-4 and UBAZ-1 whereas, the other isolates were found significantly at par in their potential of root growth promotion. Sachin et al., (2004) reported that the inoculation of Azotobacter chroococcum had positive effect on the growth parameters of bamboo and maize in pot experiment. Similar result obtained by Kanchana et al., (2014) observed that the plant dry weight of chilli was significantly increased in Azotobacter treated plants.

The highest Azotobacter population was recorded in rhizospheric soil of Mathura tea garden designated as UBAZ-5 followed by UBAZ-7 and UBAZ-1 of sugarcane and tea rhizosphere from Cooch Behar and Kalimpong, respectively. This variation could be due to differences in the availability of oxygen and/or the availability of essential elements in the soils (Line and Loutit, 1973). Azotobacter population depends on factor such as soil temperature and organic matter which degrade plant residues and help in proliferation of the micro-organisms in soil (Iswaran and Marwaha, 1981). The nitrogen fixation and its rate were found highest in UBAZ-5 followed by UBAZ-3 and UBAZ-10 at $8^{\text {th }}$ day of inoculation. The soils of tea gardens have more of organic matter which makes the soil friable and permeate the air and water for better growth of microorganism (Haris, 1981). Difference in capacity of Nfixation by Azotobacter spp. had been shown 
by Kizilkaya (2009). Sachin et al., (2004) reported that the inoculation of Azotobacter chroococcum had positive effect on the growth parameters of bamboo and maize in pot experiment. It has been concluded that best Azotobacter spp. should be isolated from rhizospheric soil where more of organic matter and rhizosphere were not disturbed which increased the yield potencial in chilli.

\section{References}

Cochran, W.G. 1950. Estimation of Bacterial Densities by Means of the "Most Probable Number". Biometrics, 6: 105-116.

Harris, R.F. 1981. Effect of water potential on microbial growth and activity. In: Parr, J.F., Gardner, W.R., Elliott, L.F. (Eds.), Water Potential Relations in Soil Microbiol., Soil Science Society America, Madison, WI, pp. 23-95.

Iswaran, V., and Marwaha, T.S. 1981. Nitrogen fixation by Azotobacter chroococcum in the presence of different phosphatic compound and its solublization. Zbl. Bakt. Parasit. Infect. Hyg., 123: 198.

Iswaran, V., and Marwaha, T.S. 1981. Nitrogen fixation by Azotobacter chroococcumin the presence of different phosphatic compound and its solublization. Zbl. Bakt. Parasit. Infect. Hyg., 123: 198.

Kanchana, D., Jayanthi, M., Usharani, G., Saranraj, P., and Sujitha, D. 2014. Interaction Effect of Combined Inoculation of PGPR on Growth and Yield Parameters of Chilli Var K1 (Capsicum annuum L.). Int. J. Microbiol. Res., 5(3): 144-151.

Kizilkaya, R. 2009. Nitrogen fixation capacity of Azotobacter spp. strains isolated from soils in different ecosystems and relationship between them and the microbiological properties of soils. J. Environ. Biol., 30(1): 73-82.

Kjeldahl Johan, Z. 1983. "A new method for the determination of nitrogen in organic bodies."Anal. Chem., 22: 36.

Line, M.A., and Loutit, M.W. 1973. Nitrogenfixation by mixed cultures of aerobic and anaerobic micro-organisms in an aerobic environment. J. Gen. Microbiol., 74: 179180.

Narula, N., and Gupta, K.G. 1986. Ammonia excretion by Azotobacter chroococcum in liquid culture and soil in the presence of manganese and clay minerals. Plant and Soil, 93: 205-209.

Sachin, F., Cakmakci, R., and Kantar, F. 2004. Sugar Beet and Barley Yields in Relation to Inoculation with $\mathrm{N}$-fixing and Phosphate Solubilizing Bacteria. Plant Soil, 265: 123129.

Sachin, F., Cakmakci, R., and Kantar, F. 2004. Sugar Beet and Barley Yields in Relation to Inoculation with $\mathrm{N}$-fixing and Phosphate Solubilizing Bacteria. Plant Soil, 265: 123129.

Subba Rao, N.S. 1986. Biofertilizer in Indian agriculture: Problems and prospects. Fert. News, 24: 84-90.

Vessy, J.K. 2003. Plant growth promoting rhizobacteria as biofertilizers. Plant and Soil, 255(2): 571 - 586.

\section{How to cite this article:}

Ambesh, B.S., A. Roy, S. Ngomle, P.M. Bhattacharya and Meena, V.S. 2017. Isolation and Evaluation of Azotobacter Spp. from Different Crop Rhizosphere. Int.J.Curr.Microbiol.App.Sci. 6(4): 883-888. doi: https://doi.org/10.20546/ijcmas.2017.604.111 